\title{
The electronic state of cerium in two palladium alloys by energy loss
}

\section{spectroscopy}

\author{
K. X. Hu ${ }^{*}$ I. R. Harris ${ }^{*}$ and I. P. Jones ${ }^{*}$ \\ * Department of Metallurgy and Materials, University of Birmingham, Edgbaston, Birmingham, \\ B15 2TT, UK
}

\section{Introduction}

Early work on the Pd-Ce system [1] showed that there is a significant range of solid solution of cerium in palladium despite the large size factor in the system. Lattice spacing and magnetic susceptibility measurement indicated that the cerium atoms are in a 4-valent state in the solid solution alloys but the valence decreases towards 3.0 in the ordered, $\mathrm{Cu}_{3} \mathrm{Au}$ type $\mathrm{Pd}_{3} \mathrm{Ce}$ compound $[1,2]$. Subsequent work [3] showed that large range ordering occurred at the $\mathrm{Pd}_{7} \mathrm{Ce}$ composition $\left(\mathrm{Pt}_{7} \mathrm{Cu}\right.$ type super lattice) and this alloy underwent an order-disorder transition on heating to $735 \pm 6^{\circ} \mathrm{C}$. The present work was undertaken to see if the proposed different valence state for Ce in $\mathrm{Pd}_{7} \mathrm{Ce}$ and $\mathrm{Pd}_{3} \mathrm{Ce}$ could be detected by energy loss spectroscopy in the TEM.

\section{Experiment}

The palladium (99.98\%) used in the present work was kindly loaned by Johnson Matthey and Co. Ltd. The $\mathrm{Pd}_{3} \mathrm{Ce}$ and $\mathrm{Pd}_{7} \mathrm{Ce}$ alloys were prepared by argon arc melting and then air-cooling to room temperature after the alloys had been heat treated at $1000^{\circ} \mathrm{C}$ for a week for homogenization. The specimens for transmission electron microscopy were prepared by conventional mechanical polishing followed by ion beam milling (GATAN PIPS) for a short time to electron transparency. In order to collect standard spectra of 3-valent $\mathrm{Ce}$ and 4-valent $\mathrm{Ce}$, we used $\mathrm{CePO}_{4} \cdot \mathrm{xH}_{2} \mathrm{O}(59.4 \%$ $\mathrm{Ce})$ and $\mathrm{CeO}_{2}$ powder $(99.9 \%$ ) from Strem Chemicals. The purity was given as $99.9 \%$. The measurement was performed with a Gatan666 Digital PEELS spectrometer attached to a FEI Tecnai F20 Schottky field emission gun transmission electron microscope operating at $200 \mathrm{keV}$, which offers an energy resolution of $0.8-0.9 \mathrm{eV}$. The spectra were corrected for dark current, readout noise and channel-to-channel gain variation.

\section{Results and discussion}

For Ce the core-loss edges include the $\mathrm{O}_{2,3}, \mathrm{O}_{1}, \mathrm{~N}_{4,5}, \mathrm{~N}_{2,3}, \mathrm{~N}_{1}, \mathrm{M}_{4,5}, \mathrm{M}_{2,3}$ and $\mathrm{M}_{1}$ edges. Of these, the $\mathrm{M}_{4,5}$ edge is best suited for studying Ce because it exhibits distinct valence-specific shapes which are separated in energy. The $\mathrm{M}_{5}$ and $\mathrm{M}_{4}$ edges arise from the two ways in which the spin quantum number, s, couples to the orbital angular momentum, 1, giving a total angular momentum, $j=1+s$. This coupling gives two peaks; $M_{5}$ from the $3 d_{5 / 2}(j=5 / 2)$ level and $M_{4}$ from the $3 d_{3 / 2}(j=3 / 2)$ level. The $\mathrm{M}_{4,5}$ edges reflect transitions of $3 \mathrm{~d}$ core electrons to unoccupied states of $\mathrm{p}$ - and $\mathrm{f}$-like symmetry. The sharp $\mathrm{M}_{5}$ and $\mathrm{M}_{4}$ peaks near the edge onsets arise from quasiatomic, dipole-allowed transitions from an initial $3 d^{10} 4 f^{n}$ state to final states of the form $3 d^{9} 4 f^{n+1}[5]$. The transitions mask the much weaker $3 \mathrm{~d} \rightarrow \mathrm{p}$ edge. The edge shapes are also little affected by the crystal field and other bonding effects.

The $\mathrm{Ce}_{4,5}$ edges of $\mathrm{CeO}_{2}$ have shapes characteristic of $\mathrm{Ce}^{4+}$ and distinct from those of the $\mathrm{Ce}^{3+}$ in $\mathrm{CePO}_{4} \cdot \mathrm{xH}_{2} \mathrm{O}$ (Fig.1). The $\mathrm{Ce}^{4+} \mathrm{M}_{5}$ and $\mathrm{M}_{4}$ edges are separated by $17 \mathrm{eV}$ and consist of two 
main symmetrical maxima at 884 and $901 \mathrm{eV}$ followed by lower intensity, broader maxima $\mathrm{Y}$ and $\mathrm{Y}^{\prime}$ at 889 and $906 \mathrm{eV}$. The main $\mathrm{M}_{5}$ and $\mathrm{M}_{4}$ maxima of $\mathrm{CeO}_{2}$ result from transitions from an atomic-like $\mathrm{f}^{0}$ ground-state configuration [4]. The $\mathrm{Y}$ and $\mathrm{Y}^{\prime}$ maxima also occur in other rare-earth dioxides and are thought to originate from transitions to $4 \mathrm{f}$ states in the conduction band [5]. Finazzi et al. [6] refer to $\mathrm{Y}$ and $\mathrm{Y}^{\prime}$ as the $\mathrm{f}^{0}$ satellites and relate their intensities to the degree of delocalization of the f-electrons. The $\mathrm{Ce}^{3+} \mathrm{M}_{4,5}$ edge shapes, intensities, and energies differ from those of $\mathrm{Ce}^{4+}$. The $\mathrm{Ce}^{3+} \mathrm{M}_{4}$ edge has a weak peak, E, at $896 \mathrm{eV}$.

From Fig. 2, we see that the Ce spectrum from $\mathrm{CePd}_{3}$ behaves more like 3-valent Ce: we can clearly see the small edge just before the main $\mathrm{M}_{4}$ edge. The spectrum from $\mathrm{CePd}_{7}$ indicates a nearly 4 valent state for the Ce atoms. Since the intensity ratio $M_{5} / M_{4}$ is sensitive to the valence state of $\mathrm{Ce}$, we intend in the future to determine the exact valence of Ce via the $\mathrm{M}_{5} / \mathrm{M}_{4}$ ratio.

4. Conclusion

PEELS is suitable for the analysis of the oxidation state of Ce using the $\mathrm{Ce}_{4,5}$ edges. The Ce atom in $\mathrm{CePd}_{7}$ alloy is close to 4 -valent Ce because of the strong hybridization of the $4 \mathrm{f}$ state of $\mathrm{Ce}$ with the $4 \mathrm{~d}$ state of $\mathrm{Pd}$. The $\mathrm{Ce}$ atom in $\mathrm{CePd}_{3}$ behaves more like 3-valent $\mathrm{Ce}$ since the $\mathrm{Ce}$ spectrum looks very like the Ce spectrum from $\mathrm{CePO}_{4} \cdot \mathrm{xH}_{2} \mathrm{O}$.

Reference

[1] I.R.Harris and M.Norman. Journal of the Less Common Metals 15 (1968) 285

[2] I.R.Harris and G.V.Raynor. Journal of Less Common Metals 9 (1965) 263

[3] D.A.Smith, I.P.Jones and I.R.Harris Journal of Materials Science Ketters. 1 (1982) 463

[4] J.C.Parlebas and A.Kotani. Journal of Electron Spectroscopy and Related Phenomena 136 (2004) 3

[5] R.C.Karnatak, J.M.Esteva, H.Dexpert, M.Gasgnier, P.E.Caro and L.Albert. Physical Review B 36(1987) 1745

[6] M.Finazzi, F.M.F.de Groot, A.M.Dias, J.P.Dappler, O.Schulte, W.Felsch and G.Krill. Journal of Electron Spectroscopy and Related Phenomena 78 (1996) 221

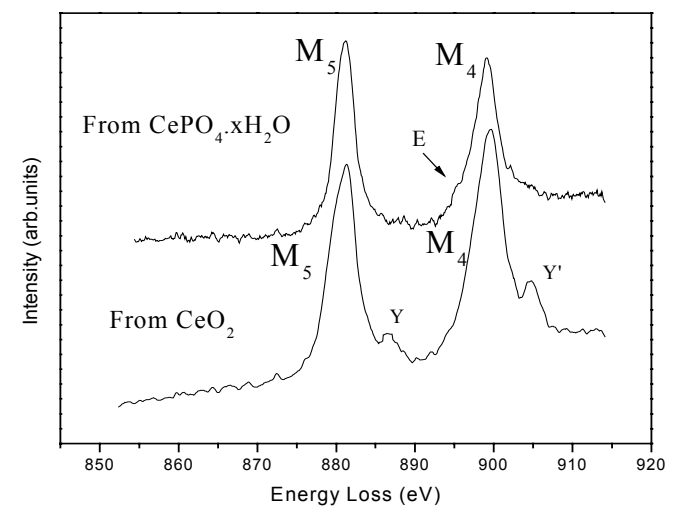

Fig.1. $\mathrm{Ce} \mathrm{M}_{4,5}$ edges of $\mathrm{Ce}^{4+}$ and $\mathrm{Ce}^{3+}$ from $\mathrm{CeO}_{2}$ and $\mathrm{CePO}_{4} \cdot \mathrm{xH}_{2} \mathrm{O}$.

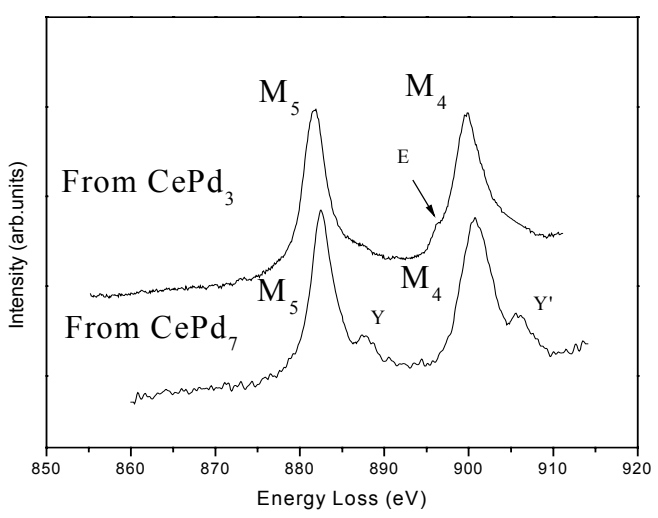

Fig.2. Ce $\mathrm{M}_{4,5}$ edges from $\mathrm{CePd}_{3}$ and $\mathrm{CePd}_{7}$. 